\title{
MENTAL HEALTH NURSES' CONTRIBUTIONS TO COMMUNITY MENTAL HEALTH CARE: AN AUSTRALIAN STUDY
}

\begin{abstract}
Australian mental health policy is focused on providing mental health care in the community setting and community mental health teams provide services to clients in a shared model with primary care. The historical literature reports that community mental health nurses' experience high levels of stress and are often allocated the most complex and challenging clients managed by the team. Yet information on their specific roles remains limited. This paper reports on research conducted at one Australian public mental health service to identify the components of the community mental health nursing role and to quantify the time nurses spent in each component during the study period.

Six focus groups were conducted with community mental health nurses to identify their perceived role within the team. Data analysis identified 18 components of which 10 were related to direct clinical contact with clients and eight covered administrative and care coordination activities. A data collection tool based on the findings of the focus groups was designed and nurses recorded workload data on the tool in 15 minute intervals over a four week period.
\end{abstract}

Seventeen nurses collected 1528 hours of data. Internal coordination of care was identified as the top workload item followed by clinical documentation and national data collection responsibilities supporting the complexity of the community mental health nursing role. The high rating attached to the internal coordination of care role demonstrates an important contribution that community mental health nurses make to the functioning of the team and the delivery of quality mental health care.

Keywords: community mental health nursing, community teams, role definition, workload components

\footnotetext{
This is the peer reviewed version of the following article: Heslop, B. and Wynaden, D. and Tohotoa, J. and Heslop, K. 2016. Mental health nurses' contributions to community mental health care: An Australian study. International Journal of Mental Health Nursing. 25 (5): pp. 426-433., which has been published in final form at http://doi.org/10.1111/inm.12225. This article may be used for non-commercial purposes in accordance with Wiley Terms and Conditions for Self-Archiving at http://olabout.wiley.com/WileyCDA/Section/id-820227.html\#terms
} 


\section{INTRODUCTION AND BACKGROUND}

For the last three decades, Australia has had a nationally coordinated approach to mental health service delivery which places importance on the provision of mental health care in the community setting (Australian Health Ministers 199219982003 2009, Council of Australian Governments 2007). Internationally, primary care services are now an important component of the continuum of mental health care provision (World Health Organization 2008). However, as primary health services struggle to meet the total mental health needs of this vulnerable population, community mental health teams from secondary mental health services provide care to clients in the community in a shared model with primary care (Keleher 2006). They care for clients in a variety of settings, for example, residential facilities, clinics, or private homes while encouraging them to engage with a general practitioner and other support and recovery services delivered by non-government and community organisations (Mental Health Council of Australia 2010).

Community mental health professionals utilise a care coordination model to improve care planning and increase the client's continuity of care and access to services outside of health. This inclusive approach aims to foster client recovery and reduce duplication of services. Care coordination involves interactions and planning between the client, clinicians, health care providers, the family and other significant stakeholders (Western Australian Department of Health 2015). It is directed at meeting the client's individual needs to enhance their independence and facilitate social connectedness while providing high quality safe mental health care during the client's transition back to primary health care and other community services. 
Mental health nurses began to practice in the community setting in the 1950s (Gournay 2000). In the early phase of community mental health care, community mental health nurses $(\mathrm{CMHN})$ were mainly involved in working with people who had schizophrenia to monitor their progress and administer and monitor medications (Green 1968). The contemporary literature expands on the original role definitions to encompass the case management role traditionally completed by a range of community mental health professionals (Burns et al. 2007, Wallace et al. 2005), providing psychoeducation (Agius et al. 2007), and liaison and advocacy services to a variety of internal and external stakeholders groups (Zeeman et al. 2002).

The literature also portrays the perception that CMHNs caseloads have always been comprised of the most difficult and challenging clients (Henderson et al. 2008a, Zeeman et al. 2002) and that CMHN's have a pivotal role in the management of individuals receiving involuntary treatment under a designated state Mental Health Act (Elsom et al. 2007). Comprehensive assessment and crisis response is also identified in the literature as a frequent role completed by CMHNs (Ng et al. 2000, Wallace et al. 2005, Zeeman et al. 2002). It is also documented that CMHNs experience high levels of work related stress and face many challenges when providing care in the community ( Happell et al. 2013b). Working with clients with complex needs, many of whom are receiving treatment involuntarily, high caseloads and responding to crisis situations adds to CMHNs fatigue and potential disillusionment with their clinical role (Bellali \& Kalafati 2006). The literature identifies that many of the aspects of the $\mathrm{CMHN}$ role, particularly care coordination aspects may not always be apparent to other team members and as a result the associated workload may not be acknowledged (Crawford et al. 2008). 
The rapid expansion of community mental health services over the last decades has seen the role of the CMHN diversify to address the changing directives in mental health policy and service delivery (Thornicroft et al. 2010). For example, many CMHNs undertake duties as authorised mental health practitioners under state and territory Mental Health Acts. These duties require them to be frontline professionals who attend acute and often distressing mental health situations that occur in the community setting. They possess a skill set to work closely with other emergency services in stressful work environments (Western Australian Office of the Chief Psychiatrist 2015). However, there remains a paucity of information on the specific clinical roles completed by CMHNs (Happell et al. 2012), and a demonstrated need for further research to provide an improved understanding of the contributions that mental health nurses make to the delivery of community mental health care (Kudless \& White 2007). This paper reports the findings of research completed at one public mental health service in Australia to identify the key components of the CMHN role. It was hypothesised that collection of evidence based data over a four week period would highlight the significant contribution to community mental health service delivery that community mental health nurses currently make.

\section{METHOD}

The community mental health service where this research was completed is comprised of four community mental health continuing care teams, an early episode psychosis team and an assertive community treatment team. CMHN's make up the largest component of the community service with 14.5 full time equivalent (FTE) clinical mental health nurses and 5 FTE clinical nurse specialists. Weekend coverage is provided by two clinical nurses.

Weekend referral is via all community teams along with referral from mental health triage. After hours services are provided by a community assertive treatment team (CATT) that 
operates from 1430 to $2300 \mathrm{hrs}$ with further on call facilities available overnight. The mental health service is one of five in the health region that covers a catchment area of almost 5,000 square kilometres, with a population of 840,000 . At the time of data collection, 280 clients aged between 18 and 65 years of age were being case managed by CMHNs who participated in this study. Caseload ratios varied from $10-27$ clients per clinician.

The research was viewed as minimal risk and was registered as a quality improvement activity at the health service and university ethics approval was obtained. The objectives were to:

a) Identify the components of the CMHN role and develop a data collection tool based on the identified components;

b) Collect workload data from each CMHN at the service who agreed to participate in the research over a four week period to quantify the components of the role.

Six focus groups over a six week timeframe were conducted with CMHNs in 2013. Each focus group lasted approximately one hour and was digitally recorded and then transcribed verbatim. Content analysis of the transcripts was completed by two members of the research team to identify the evolving components and dimensions of the CMHN role. The collated findings from the preceding focus groups were then presented to participants at subsequent focus group sessions. Participants then discussed and revised the findings until data saturation was reached during the sixth focus group and consensus on the components and their defining dimensions was obtained. Eighteen components were identified (10 related to clinical contact with clients and eight covered administrative and care coordination activities). The identified components were then incorporated into a data collection tool with an accompanying legend that outlined the dimensions of each component. (See Figure 1 and 2). 
Insert Figure 1 and 2 here

Education sessions were conducted with CMHNs to familiarise them with the data collection tool and to answer any queries they had about coding of data during the four week period. Data were entered by each CMHN at 15 minute intervals between the hours of $8 \mathrm{am}-5 \mathrm{pm}$ during their rostered shifts. CMHNs reported that the data collection tool was easy to use and no major issues were identified during the four week period. Collected data sheets were coded by the research team and data were entered into the Statistical Package for the Social Sciences, Version 18.0 (Statistical Package for Social Sciences 2012) for analysis.

\section{RESULTS}

Thirteen clinical nurses and four clinical nurse specialists agreed to participate in the research which represented an $89 \%$ participation rate. One thousand five hundred and twenty eight hours (of a possible 2,584 hours, 59\%) of data were collected by the $17 \mathrm{CMHNs}$ over the four week period. The $41 \%$ of uncompleted data collection accounted for annual leave, accrued days off, sick leave, CMHNs working part time and in one instance the data collection tool being misplaced.

Ten of the CMHNs were authorised mental health practitioners and of these, four were clinical nurse specialists. The remaining six authorised mental health practitioners were clinical nurses (representing $46 \%$ of clinical nurses at the service). Sixty five percent of the CMHNs were aged between 40-49 years. Half of the nurses had worked in mental health for more than 10 years but only $23 \%$ had completed further post graduate education. 
Internal coordination of care accounted for 285 hours $(18.7 \%)$ of the CMHN workload over the four week period followed by clinical documentation and entry of national mental health outcome data 283.3 hours $(18.5 \%)$. This was followed by 175 hours $(11.5 \%)$ of workload allocated to monitoring clients' psychopathology, while 119.3 hours $(7.8 \%)$ of time was dedicated to assertive outreach work. The allocation of additional hours of the CMHN workload is outlined in Table 1. Category 18 "Other duties" accounted for 81 hours $(5.4 \%)$ of the workload and covered activities such as participating in workforce recruitment panels, completing rostering tasks for junior staff and managing other human resource issues not identified in category 16 "Mentoring, supervision and support to clinicians".

Table 1: Allocation of components of CMHN role over the 1528 hours of data collection

\begin{tabular}{|lcc|}
\hline COMPONENTS & HOURS & \% \\
\hline Internal coordination of care & 285.0 & 18.7 \\
\hline $\begin{array}{l}\text { Clinical documentation and national data collection } \\
\text { responsibilities }\end{array}$ & 283.3 & 18.5 \\
\hline Monitoring psychopathology & 175.3 & 11.5 \\
\hline Assertive outreach & 119.3 & 7.8 \\
\hline Consultation and liaison & 109.8 & 7.2 \\
\hline Psychopharmacology & 109.0 & 7.1 \\
\hline Other duties & 81.8 & 5.4 \\
\hline Mental State and risk assessment & 79.5 & 5.2 \\
\hline Therapeutic relationship/engagement & 67.3 & 4.4 \\
\hline Education formal/informal & 59.3 & 3.9 \\
\hline Psychotherapeutic/treatment interventions & 35.0 & 2.3 \\
\hline Strategic Team Planning & 34.3 & 2.2 \\
\hline Promotion of physical health/metabolic screening & 27.8 & 1.8 \\
\hline Mentoring, supervision and support to clinicians & 25.0 & 1.6 \\
\hline $\begin{array}{l}\text { Interdisciplinary team education, organisation and } \\
\text { management }\end{array}$ & 14.5 & 0.9 \\
\hline Shared care with primary care & & \\
\hline Functional assessment & 7.5 & 0.6 \\
\hline Responsibilities under the Mental Health Act & 6.5 & 0.5 \\
\hline
\end{tabular}

\section{DISCUSSION}


The findings of this study highlight the value of the internal coordination of care role completed by CMHN to the function of the team and client outcomes. For example, negotiating issues such as bed availability for client admissions, providing support to carers and family members while negotiating with other health professionals to find resolutions to clinical problems that arise in daily practice. In completing this role, CMHNs demonstrate well developed networking and capacity building strengths along with advanced skills in problem solving and the ability to make decisions that ensure the service is able to rapidly respond to a variety of demands. Similarly, Cosgrave et al (2015) reported that CMHNs were frequently asked to assist other health professionals to manage challenging clients which added to their workload. However, this assistance, was mostly unable to be reciprocated due to the nursing specific interventions required (Cosgrave et al. 2015). While the internal coordination of care role has previously been documented in nursing literature, the findings of this study will assist services to quantify this role and to determine the number of nursing full time equivalent community appointments required by the service (Burnard et al. 2000, Henderson et al. 2008b; Jacobs et al. 2006). However, the need for further research to compare workload allocation and complexity of CMHNs with other community mental health professionals is also apparent to the ongoing composition of effective community teams. These comparisons would also promote an increased understanding of the CMHN role within the team and ensure equity in workloads across the team.

Completing clinical documentation and entering case mix collection data was the second largest component of the CMHN workload after internal coordination of care. This finding is not surprising as higher levels of documentation and accountability would be generated from the large clinically focus internal coordination of care component that CMHNs completed (Brophy et al. 2014). CMHNs also spent a large proportion of their time in monitoring 
clients' psychopathology, in consultation and liaison roles and in providing assertive outreach which also require detailed documentation to meet service and state mental health requirements. For example, if police or emergency services assist CMHNs who are undertaking duties as authorised mental health practitioners, the appropriate documentation will need to be completed once the client situation is resolved. Consequently, the skill mix that CMHNs bring to community teams generates work that necessitates the completion of large amounts of clinical documentation and case mix collection data entry and this needs to be accounted for in workload allocation. Similarly, other authors have found that these duties constitute a large component of the CMHN role which can impacted negatively on time spent in face to face contact with clients (Jacobs et al. 2006, Ng et al. 2000, Wallace et al. 2005, Zeeman et al. 2002). In the current risk averse health care environment, the amount of clinical documentation that must be completed by health professionals is an increasing issue for services to effectively manage. National data collection entry on all clients accessing public mental health services is now well established and at a clinical level they provide valuable insights into client outcomes and nationally about service delivery and future planning strategies. Staff access to improved technologies and equitable workload distributions may reduce individual workload hours associated with these roles.

It is very concerning CMHNs only apportioned $1.8 \%$ of their time to the physical health of their clients. This equated to 27.8 hours or less than two hours per clinician during the total collection phase and supports the premise that mental health clinicians view their core business as assessing and treating mental illness whilst physical health issues are viewed as less important or other health professionals' responsibility. Beebe et al (2011) highlighted that many physical health issues in this group of clients remain undiagnosed and untreated (Beebe et al. 2011) and that there is an apparent lack of consideration to address the client's 
physical health issues by CMHNs despite well documented evidence of high morbidity rates in this group. The need for increased physical health training and monitoring for clients with severe mental illness is evident with the study findings and CMHNs have an ethical and professional responsibility to check a client's physical health routinely (Gimblett, 2015). Exhaustive studies correlate severe mental illness with poorer health outcomes (Happell et al. 2015, Happell et al. 2013a, Hyland et al. 2003, Nash 2011, Scott \& Happell 2011). This result reinforces what the literature already highlights that there has been no improvement at the clinical level of health screening and monitoring over the last decade to address the physical health needs of this cohort (Happell et al. 2015).This is further reinforced when considering shared care with primary care occupied less than one percent of CMHNs' workload. As CMHNs have a key responsibility in administering antipsychotic medications, the lack of monitoring to detect frequent adverse drug reactions or the unintended consequences of treatment is of concern as psychiatric medications have strong links with poor physical health outcomes (Nash 2011). In addition, clients need to be better educated about adverse drug reactions they may experience as a report by the Healthcare Commission (2007) found that $34 \%$ of clients that they surveyed did not have this knowledge provided to them (Council of Australian Governments 2007).

CMHNs only allocated approximately one hour each week to informal and formal education. A limitation of the data collected was the failure to distinguish between the education clinicians received and the education that they provided to others. However, it can be assumed that the time CMHNs spent providing education to clients in the area of health promotion and to increase the client's knowledge of the medications they were taking was limited. Expansion of the CMHN role could be in the area of health promotion and the maintenance of the client' physical and mental health and lead to community mental health 
nurses leading community group exercise programs; for example, a regular walking group for clients with severe mental illness (Richardson et al. 2005).

The lack of time spent by CMHNs on clinical supervision was also alarming and not in keeping with current literature that promotes clinical supervision as important to reduce burnout, increase recruitment potential and reduce attrition in the workforce (Chana et al. 2015, Edwards et al. 2006, Onyett 2011). CMHNs must seek opportunities to engage more fully in educational and professional development such as clinical supervision.

\section{Conclusion}

This research sought to articulate the CMHN role and to quantify the components of that role. As nurses provide the bulk of the community mental health workforce they are well placed to champion further initiatives within organisations to improve the health of clients in their care. While CMHNs play important roles in the provision of care in the community setting their lack of responsibility and accountability in regard to the provision of physical health screening for clients in their care only reinforces that until someone takes responsibility for the physical health of people with a mental illness this group will continue to have high levels of mortality and morbidity associated with physical illness. The gap in life expectancy of this group when compared to the general population will continue to increase. Redefining and prioritising the roles of CMHNs to support a more recovery focus for their clients could help reduce the health inequality currently seen in this population. The important roles that CMHNs complete within multidisciplinary teams need to be accounted for in the selection of team members and in the overall distribution of caseload numbers to team members. 


\section{REFERENCES}

Agius, M. Shah, S. Ramkisson, R. Murphy, S. \& Zaman, R. (2007). Three year outcomes of an early intervention for psychosis service as compared with treatment as usual for first psychotic episodes in a standard community mental heaclth team - final results. Psychiatria Danubina, 19(3), 130-138.

Australian Health Ministers. (1992). National Mental Health Policy: National Mental Health Strategy. Canberra: Commonwealth Department of Health and Family Services

Australian Health Ministers. (1998). Second National Mental Health Plan: National Mental Health Strategy. Canberra: Commonwealth Department of Health and Family Services.

Australian Health Ministers. (2003). Third National Mental Health Plan: National Mental Health Strategy. Canberra: Commonwealth Department of Health and Family Services.

Australian Health Ministers. (2009a). Fourth National Mental Health Plan: National Mental Health Strategy. Canberra: Commonwealth of Australia.

Beebe, L. Adams, S. \& El-Mallakh, P. (2011). Putting the "evidence" in evidence based practice: Meeting research challenges in community psychiatric settings. Issues in Mental Health Nursing, 32, 537-543.

Bellali, T. \& Kalafati, M. (2006). Greek psychiatric care reform: New perspectives and challenges for community mental health nursing. Journal of Psychiatric and Mental Health Nursing, 13, 33-39.

Brophy, L. Hodges, C. Halloran, K. Grigg, M. \& Swift, M. (2014). Impact of care coordination on Australia's mental health service delivery system. Australian Health Review, 38(4), 396-400. doi: 10.1177/1440783305057077

Burnard, P. Edwards, D. Fothergill, A. Hannigan, B. \& Coyle, D. (2000). When the pressure's too much. Nursing Times, 96(19), 28-30.

Burns, T. Catty, J. Dash, M. Roberts, C. Lockwood, A. \& Marshall, M. (2007). Use of intensive case management to reduce time in hospital in people with severe mental illness: systematic review and meta-regression. British Medical Journal, 335(7615), 336. doi: $10.1136 / \mathrm{bmj} .39251 .599259 .55$

Chana, N. Kennedy, P. \& Chessell, Z. J. (2015). Nursing staffs' emotional well-being and caring behaviours. Journal of Clinical Nursing, 24(19-20), 2835-2848. doi:

10.1111/jocn.12891

Cosgrave, C. Hussain, R. \& Maple, M. (2015). Factors impacting on retention amongst community mental health clinicians working in rural Australia: a literature review. Advances in Mental Health: Promotion, Prevention and Early Intervention. 13(1), 5871. doi: org/10.1080/18374905.2015.1023421

Council of Australian Governments. (2007). National Mental Health Report 2007: Summary of Twelve Years of Reform in Australia's Mental Health Services under the National Mental Health Strategy 1993-2005. Canberra: Commonwealth Department of Health and Ageing. 
Crawford, P. Brown, B. \& Majomi, P. (2008). Professional identity in community mental health nursing: A thematic analysis. International Journal of Nursing Studies, 45(7), 1055-1063. doi: 10.1016/j.ijnurstu.2007.05.005

Edwards, D. Burnard, P. Hannigan, B. Cooper, L. Adams, J. Juggessur, T. . . Coyle, D. (2006). Clinical supervision and burnout: the influence of clinical supervision for community mental health nurses. Journal of Clinical Nursing, 15(8), 1007-1015. doi: 10.1111/j.1365-2702.2006.01370.x

Elsom, S. J. Happell, B. \& Manias, E. (2007). Exploring the expanded practice roles of CMHNs. Issues in Mental Health Nursing, 28(4), 413-429.

Gimblett, D. (2015). Monitoring physical health in patients with serious mental illness. Mental Health Practice, 18(5), 20-23. doi: org/10.7748/mhp.18.5.20.e929

Gournay, K. (2000). Role of the community psychiatric nurse in the management of schizophrenia. Advances in Psychiatric Treatment 6 (4) 243-249.

Greene, J. (1968). The psychiatric nurse in the community nursing service. International Journal of Nursing Studies, 5, 175-184.

Happell, B. Galletly, C. Castle, D. Platania-Phung, C. Stanton, R. Scott, D. . . Furness, T. (2015). Scoping review of research in Australia on the co-occurrence of physical and serious mental illness and integrated care. International Journal of Mental Health Nursing, 24(5), 421-438.

Happell, B. Hoey, W. \& Gaskin, C. (2012). CMHNs, caseloads and practices: A literature review. International Journal of Mental Health Nursing, 21(2), 131-137.

Happell, B. Platania-Phung, C. \& Scott, D. (2013a). Mental Health Nurse Incentive Program: facilitating physical health care for people with mental illness? International Journal of Mental Health Nursing, 22(5), 399-408. doi: 10.1111/inm.12006

Happell, B. Gaskin, C. J. Hoey, W. Nizette, D. \& Veach, K. (2013b). The activities that nurses working in community mental health perform: a geographical comparison. Australian Health Review, 37(4), 453-457. doi: 10.1071/ah13045

Henderson, J. Willis, E. Walter, B. \& Toffoli, L. (2008a). Community mental health nursing: keeping pace with care delivery? International Journal of Mental Health Nursing, 17(3), 162-170. doi: 10.1111/j.1447-0349.2008.00528.x

Henderson, J. Willis, E. Walter, B. \& Toffoli, L. (2008b). Measuring the workload of community mental health nurses: a review of the literature. Contemporary Nurse, 29(1), 32-42.

Hyland, B. Judd, F. Davidson, S. Jolley, D. \& Hocking, B. (2003). Case managers attitudes to the physical health of their patients. Australian and New Zealand Journal of Psychiatry, 37, 710-714.

Jacobs, S. Hughs, J. Challis, D. Stewart, K. \& Weirner, K. (2006). Care managers' time use: Differences between community mental health and older people's services in the United Kingdom. Care Management Journals, 7, 169-178.

Keleher, H. (2006). Community-based Shared Mental Health Care: A Model of Collaboration? Australian Journal of Primary Health, 12(2), 90 - 96

Kudless, M. W. \& White, J. H. (2007). Competencies and Roles of Community Mental Health Nurses. Journal of Psychosocial Nursing \& Mental Health Services, 45(5), 3644.

Mental Health Council of Australia. (2010). Community Mental Health and Primary Mental Health Care Background Paper from http://mhaustralia.org/sites/default/files/imported/component/rsfiles/publications/Com munity_Mental_Health_and_Primary_Mental_Health_Care_Background_Paper_July 2010.pdf 
Nash, M. (2011). Improving mental health service users' physical health through medication monitoring: a literature review. Journal of Nursing Management, 19(3), 360-365. doi: 10.1111/j.1365-2834.2011.01244.x

Ng, D. T. F. Chan, S. W. C. \& MacKenzie, A. (2000). Case management in the community psychiatric nursing service in Hong Kong: Describing the process. Perspectives in Psychiatric Care, 36, 59-66.

Western Australan Office of the Chief Psychiatrist. (2015). Authorised Mental health practitioners. Perth, Western Australia: Government of Western Australia. Retrieved from http://www.chiefpsychiatrist.health.wa.gov.au/act/amhp.cfm.

Onyett, S. (2011). Revisiting job satisfaction and burnout in community mental health teams. Journal of Mental Health, 20(2), 198-209. doi: 10.3109/09638237.2011.556170

Richardson, C. R. Faulkner, G. McDevitt, J. Skrinar, G. S. Hutchinson, D. S. \& Piette, J. D. (2005). Integrating Physical Activity Into Mental Health Services for Persons With Serious Mental Illness. Psychiatric Services, 56(3), 324-331. doi: doi:10.1176/appi.ps.56.3.324

Scott, D. \& Happell, B. (2011). The high prevalence of poor physical health and unhealthy lifestyle behaviours in individuals with severe mental illness. Issues in Mental Health Nursing, 32(9), 589-597. doi: 10.3109/01612840.2011.569846

Statistical Package for Social Sciences. (2012). SPSS for windows (Vol. 18). Chicago, IL, USA: SPSS Inc.

Thornicroft, G. Alem, A. Dos Santos, R. A. Barley, E. Drake, R. E. Gregorio, G. . . . Wondimagegn, D. (2010). WPA guidance on steps, obstacles and mistakes to avoid in the implementation of community mental health care. World Psychiatry, 9(2), 67-77. doi: 10.1002/j.2051-5545.2010.tb00276.x

Wallace, T. O'Connell, S. \& Frisch, S. R. (2005). What do nurses do when they take to the streets? An analysis of psychiatric and mental health nursing interventions in the community. Community Mental Health Journal, 41(4), 481-496.

Western Australian Department of Health. (2015). Care coordination for mental health Perth, Western Australia: Department of Health. Retrieved from http://healthywa.wa.gov.au/Healthy-WA/Articles/A E/Care-coordination-for-mentalhealth.

World Health Organization. (2008). Integrating mental health into primary care: A global perspective. Geneva: World Health Organisation.

Zeeman, Z. Chapman, R. Wynaden, D. McGowan, S. Lewis, M. Austin, J. \& Finn, M. (2002). Community mental health care: documenting the role of the nurse. Contemporary Nurse, 12(2), 112-123. 
